\title{
SOCIAL INDICATORS AND HEALTH-FOR-ALL
}

\author{
FraNK M. ANDREWS \\ Center for Population Planning and Institute for Social Researeh. \\ University of Michigan. U.S.A.
}

\begin{abstract}
It is proposed that concepts and results emerging in the 15 year history of the social indicators movement can contribute to the design and implementation of the information systems that will be required if primary health care is to be extended to all people by the year 2000 . an ambitious goal set by a recent international conference. Six methodological themes are identifed and discussed. These stress the importance of: (1) including normative outcome measures among the indicators. (2) tapping both objective health conditions and subjective perceptions, (3) incorporating theoretical models of how the health care system works, (4) organizing results in a set of health 'accounts' which have certain pre-specified relationships to one another, (5) describing key health phenomend at several different levels of specificity and (6) devoting substantial attention to evaluating and improving data quality. These six themes can be used both as guiding principles to shape the development of health information systems and as criteria for evaluating such systems.
\end{abstract}

\section{INTRODUCTION}

Achieving primary health care for all people of the world by the year 2000 , a goal adopted at a major international conference in 1978, poses formidable challenges that will require, among other things, effective information systems to provide program guidance and evaluation. The social indicators movement', which has developed rapidiy over the past 15 years, can be regarded as a concerted effort to develop broad-based information systems dealing with societal functioning. It is the thesis of this paper that some of the key methodological ideas, concepts, and approaches that have been developed and/or used within the social indicators movement can contribute to achieving the goal of health-for-all. This paper discusses six specific themes from the social indicators movement that could help to guide and form the expanded information system that will be required if primary health care is to be made universally and continuously available to all people.

\section{Health for all}

The goal of providing primary health care to all people of the Earth by the year 2000 was enunciated at an international conference co-sponsored by the World Health Organization and the United Nations Children's Fund and held in Alma-Ata. U.S.S.R., in September 1978. A major outcome of this conference was the Declaration of Alma-Ata [1], a document that reflects both the noble ambitions held by the conference participants and the enormous challenges that such ambitions pose.

The Declaration includes statements about 'health' and 'primary health care' that are helpful in defining the scope and meaning of the health-for-all goal. Section I of the Declaration notes that "health ... is a state of complete physical. mental and social wellbeing. and not merely the absence of disease or informity...". And Section VII, discussing primary health care. states that it includes a wide range of traditional health topics (provision of drugs. treatment of disease and injury, immunization against infectious diseases. maternal and child health, concerns for safe water and proper nutrition, etc.), and that primary health care also involves "all related sectors and aspects of national and community development. in particular agriculture, animal husbandry, food industry, education. housing. public works communications and other sectors...".

The broad range of concerns included in primary health care' and the large number of societal sectors that are linked to primary health care suggest the need for effective information systems to guide policy formation. implementation activities, and evaluation. The crucial role played by health information systems is well recognized in a World Health Organization document addressed to formulating strategies for meeting the goal of health-for-all [2. particularly in para. $44,61-67,88]$, and WHO has already begun to propose indicators for such systems [3].

Of course, some health information systems already exist, and they vary in their effectiveness from country to country. However. in many parts of the world perhaps in all parts--health information systems can be improved. Learnings from the social indicators movement suggest some of the kinds of improvements that might be made.

\section{The social indicutors mocement}

The modern social indicators movement began in the mid-1960"s and has been in vigorous world-wide development for the past 15 years. It had its origin in the realization that traditional economic statistics did not provide the broad-based information needed for monitoring social change, evaluating social programs, guiding policy development, and-in general-assessing the quality of life or levels of well-being. This is not the place to present a history of the social indicators movement, and others have assembled annotated bibliographies of some of the more important literature [4]. but suffice it to say that significant efforts have been devoted by soctal scientists. statistjcians. government administrators, and others to laying the conceptual and operational foundations on which more broadly-based social information systems 
can be built. These activities have occurred in a number of important universities and research institutes around the world, and in selected governmental units at virtually all levels, including international organizations-for example, the World Health Organization, the United Nations, Education, Scientific, and Cultural Organization, and the Organization for Economic Cooperation and Development-and governments of individual countries, states, provinces, counties, and cities. At the national level, most of the more developed countries have published some kind of social indicators report within the past few years, and so also have some of the developing countries. The social indicators movement even has its own international professional journal, Social Indicators Research.

Discussed in the pages that follow are six methodological themes from the social indicators movement that could guide development of information systems oriented to achieving the goal of health-for-all.

These six themes are:

1. The importance of measuring normative outcomes;

2. The importance of measuring both objective conditions and subjective perceptions of those conditions;

3. The importance of linking indicators to theoretical models of how societal systems function;

4. The importance of assembling indicators into a coherent, articulated social accounting system or information framework:

5. The importance of monitoring indicators at several different levels of specificity; and

6. The importance of devoting careful attention to the quality of measurement.

These six themes are certainly not unique to the social indicators movement, and some are present in the current implementation or development plans for some health information systems. However, few if any health information systems incorporate all of these themes, and each can make an important contribution.

\section{SIX THEMES TO GUIDE DEVELOPMENT OF HEALTH INFORMATION SYSTEMS}

\section{Normative outcomes}

One of the important perspectives of the social indicators movement is the view that it is desirable to have measures of outcomes that can be evaluated normatively-i.e. indicators about which there are prevailing values that enable one clearly to assess whether the situation is good or bad, better or worse, improving or deteriorating, etc. This is in contrast (and in addition) to the assembling and monitoring of more traditional 'input' indicators.

The field of health provides some examples of this contrast that have been widely cited in the social indicators literature. For example, as indicators of the quality of health care one sometimes sees statistics describing the number of hospital beds, or the number of doctors, available to a population or in an area. While this is important information, such data do not directly indicate the extent to which people have good health, which--after all--is the basic reason for having hospital beds and doctors. Furthermore, in some circumstances it is not clear how a change in an input indicator, such as the number of hospital beds, is to be interpreted: would a decrease in the number of beds indicate improving health levels (less need for hospital services), or deteriorating health levels (because needed hospital services were not available), or merely a change in hospital practices that affected efficiency of resource utilization but no change in health levels? From data on hospital beds alone, one could not tell. The social indicator movement's theme on the importance of measuring normative outcomes suggests that a health information system should include some direct measures of health status to supplement the traditional input indicators.

Numerous examples of output indicators for which there is a direct normative interpretation can be found in social indicator publications. Social Indicators $I I I$, a publication of the United States government [5], includes data on life expectancy, ageadjusted death rates, infant mortality rates, and disability days per person. Less traditional but equally direct measures have been proposed by the Organization for Economic Cooperation and Development [6] for inclusion in internationally comparable surveys of well-being: people's own responses as to (a) whether their eyesight is good enough (after correction if necessary) to read ordinary newspaper print, (b) whether they can hear normal conversations, (c) how much difficulty they would have in walking up and down stairs, or (d) running 100 meters, or (e) cutting their own toenails. If one were to observe significant changes over time-or significant differences between groups of people-in normative output indicators such as these, one could make immediate interpretations about how health levels were ehanging, or about which groups had better health.

Once the basic proposition about the importance of including normative output indicators in an information system has been made, their usefulness is readily apparent, and this proposition can become a guiding principle for the development or extension of a health information system.

\section{Complementary objective and subjective information}

A second theme of the social indicators movement points to the importance of monitoring both the 'objective' states of affairs and people's 'subjective' perceptions and evaluations of those affairs. With specific respect to health, it will be helpful to have data not only on health conditions as these are diagnosed and reported by physicians and other health professionals (the 'objective' data), but also on how people assess their own levels of health (the "subjective' information). Many broad-based definitions of health require, among other things, that a person feel healthy in order for him or her to be classified as healthy. Note, for example, the inclusion of the notions of "physical, mental and social well-being" in WHO's definition of health cited previously in this paper.

The reason for monitoring both objective and perceptual indicators is that experience has shown that they often show only modest covariation [7-9]. The messages one receives from the objective indicators are often not the same as what one receives from the 
subjective data. and-many would argue-a person's own sense of his or her health is at least as important as how healthy some "expert" may say that person is. In short, the objective and subjective indicators complement each other; neither type of indicator by itself is sufficient; together they provide a more complete picture.

Recent work in Australia by Armstrong [10] and in the United States by Zautra and his colleagues $[11,12]$ has explored development of a health policy model that takes explicit account of people's own evaluations of their health and of the health services available to them. Armstrong writes:

Explicit in this research is the assumption that policies are intended to meet the needs of the community. Discrepancies between perceptions of need by different participants may mean a mismatch between the ways in which resources are allocated, the needs they are intended to meet, and the subsequent effects of policy measures $[10$, p. 251].

Although this work carries the idea of building subjective social indicators into a health information system further than has been done previously, the basic idea is not new. The idea is clearly a good one, and this theme from the social indicators movement provides another principle that can guide development of an information system intended to help deliver primary health care to all by the year 2000 .

\section{Social indicators and theoretical models}

A third theme from the social indicators movement, extensively pursued by Kenneth Land $[13,14]$, argues that a theoretical model describing how a social system works provides crucial guidance on two important topics: (a) the selection of indicators to be monitored, and (b) the full meaning (i.e. implications) of changes in indicator values. Land's original writings were not directed specifically to the provision of primary health care, but his basic insights seem highly applicable to this specific domain. Just in the health area alone there are nearly an infinite number of indicators that one might monitor. How should one choose among these indicators? The proposal that one use a theoretical model requires that first one develop a theory of how the various components of a health care system are linked together, and that one then choose indicators that allow one to monitor how effectively inputs to the system (e.g. trained persons, money, other resources) are transformed by a set of intermediate processes (e.g. clinic or hospital services) into the intended outputs-healthy people.

Of course, it is unlikely that any existing model will prove entirely adequate. As knowledge accumulates, one can hope for improvements in the model as well as the indicators. However, even an imperfect model can provide conceptual coherence-i.e. a focus and organizing framework-for an information system that it would otherwise lack, and serve as a base on which later refinements can be built.

Furthermore, experience in the social indicators movement suggests that a theoretical model for one social system. once developed, may suggest linkages to other social systems. For example, there is accumulating evidence that the economic-production system has important influences on the health care system.
Dooley and Catalano have recently reviewed the research literature on relationships between economic changes (e.g. changes in unemployment levels) and levels of mental health and have developed a crosssectoral model which accommodates the hypotheses and findings from over 100 publications [15].

Thus this third theme from the social indicators movement suggests that the development of a health information system oriented toward achievement of the health-for-all goal should include theoretical modeling of how the system for providing primary health care actually works. Progress on models and indicators can be expected to be mutually supportive: better data can help the modelers produce more complete and valid models; and better models can suggest improvements and additions to the indicators.

\section{Social accounting systems}

The idea that social indicators may be assembled into-or provide the raw material for-a social accounting system has been inspired by an analogy with economic indicators. The notion of an 'accounting system' has been a fruitful one for the field of economics, and could prove equally useful in the health area. The key notions are that comprehensive information about inputs and outputs are assembled into a small number of distinct and meaningful categories (e.g. capital, labor, consumer goods, services, etc.) and that there exist within the system a set of pre-defined relationships such that various quantities should 'balance'.

Although the social indicators movement has not yet found ways to assemble social indicators into elegant full-fledged social accounting systems, the basic idea of trying to develop a coherent, organized information framework within which indicators pertaining to a particular area of interest could be assembled has been recognized as attractive [16]. Within the specific area of primary health care there surely are lawful relationships between such entities as the training of medical personnel at one period. the availability of people with health-care skills in a later period. the actual provision of health care, and the health status of a population. While accounting systems relevant to provision of primary health care may be, for many years, less elegant than some of the economic accounting systems, a set of 'accounts'. even in preliminary form, promise to be useful in a health information system.

Fagnani and Dumenil have been experimenting with just such a set of accounts for the French health care system [17]. Their accounts assemble and interrelate indicators that tap three major domains: information on the state of people's health, information on the health care provider system, and information on the health insurance system. What is important in the context of the present paper about their work is not the particular details but rather the example they provide. Here is an information framework that can array a broad range of health data for a particular country in a coherent way.

Of course, this fourth theme from the social indicators movement-the desirability of developing sets of social accounts-is not unrelated to the theoretical modeling theme discussed previously. Ideas about how a primary health care system works. as summar- 
ized in a theoretical model. will have an important impact on the design of the accounts that organize and portray data about the system.

\section{Indicators at several levels of specificity}

It has become common practice in the social indicators movement to develop indicators at several different levels of specificity. Highly general, or global, indicators are complemented by an array of more specific indicators. For example, in studies of perceived well-being, a general measure based on people's own evaluations of their life as a whole' usually is accompanied by their assessment of more specific life concerns, such as housing, job, family, health, and the like $[18,19]$. The same strategy has also been employed with respect to the so-called 'objective' indicators, though here questions sometimes arise regarding the appropriateness of the global indicator. (With objective measures, unlike the perceptual measures, there often is no independent measurement of the global indicator, which instead is merely a weighted composite of the more specific indicators.) Although most current systerns of indicators do not have more than two levels of specificity represented, there is no inherent reason why the number of levels could not be greater.

Having indicators at several different levels of specificity has numerous advantages. (a) Indicator overload - the presence of more data than even the experts in a field can easily comprehend-is a potential problem, and the summary provided by the more general indicators is one solution. (b) The global indicators are particularly helpfui to non-specialists (a group that includes many policymakers), whose interests often do not extend beyond the most general level. (c) Global indicators, if they are separately measured and not just composites of the more specific indicators, have an important scientific function: They stand as important 'dependent variables' in their own right, ready to play a role in basic research aimed at understanding what specific factors influence the more general one. (d) The more specific indicators, on the other hand, provide the details that explain why a more global indicator changes over time (or varies from group to group, or from place to place), and they provide the concrete information needed for policy formation and program implementation.

The idea of using measures at different levels of specificity is wide-spread in social indicators work and could be usefully incorporated in an information system focused on primary health care. There is, in fact. already some work along these lines in the health area. Chen, for example, has proposed a general 'population health status' indicator derived from more specific data on life expectancy and disability [20], and the U.S. Department of Agriculture has published a health status indicator for each county in the United States based on a combination of the infant mortality rate, the total mortality rate, and the mortality rate from influenza and pneumonia [21].

The practice of including measures at several levels of specificity in an information system is not original with the social indicators movement and, as just noted, has already influenced the construction of some health indicators. Precisely because of its proven usefulness, this idea is worth incorporating in an information system oriented toward the provision of primary health care for all by the year 2000 .

\section{Data quality}

The sixth and final theme that I wish to note as being present in the work of the social indicators movement is a persistent concern for the quality of measurement. From a theoretical perspective, the point to be made is obvious: An information system will be of little use if its data are inaccurate. However. the practical difficulties of assembling reasonably valid data are, in many cases. immense. This is not the place to elaborate on all the ways that administrative records, sample-survey interviews, bureaucratic reports, and many other sources of data can provide imprecise and/or biased results. What needs to be noted, however, is that a strong concern for data quality ought to be a part of any effort to develop a primary health care information system. Significant resources should be provided for investigating the quality of current data and finding ways to improve the accuracy of future measurements.

\section{SUMMARY AND IMPLICATIONS}

This paper has considered how concepts and results emerging in the fifteen year history of the social indicators movement can be applied toward the goal of extending primary health care to all people by the year 2000 . We have observed that the goal, as enunciated at the 1978 Alma-Ata Conference, is broad and ambitious, and that its achievement will require effective planning, coordination, monitoring and evaluation of many programs undertaken by the health sector as well as other sectors. Planning. coordination, monitoring, and evaluation all require information-lots of information, gathered on a continuous basis over an extended time. Such information is the product of information systems, and it is the thesis of this article that the social indicators movement can contribute to the design. development, and implementation of such information systems.

Six themes that characterize work in the social indicators movement have been identified, and it is proposed that these themes be included among the guiding principles that shape the development of a primary health care information system, and among the criteria against which existing information systems are evaluated.

It is suggested that a primary health care information system should: (1) include normative outcome measures; (2) tap both objective conditions and subjective perceptions: (3) incorporate theoretical models of how the health care system works: (4) organize its results in a coherent framework that might consist of a set of 'health accounts' with certain pre-specified relationships to one another: (5) describe key health phenomena at several different levels of specificity: and (6) devote substantial attention to evaluating and improving the quality of its own data.

These themes from the social indicators movement. stated here in prescriptive form, represent some general methodological contributions to achieving the goal of health for all by the year $2000^{\circ}$. 


\section{REFERENCES}

1. World Health Organization. Primary Heahh Care: Report of the Internutional Conference in Primary Health Care. Alma-Ata. USSR, 6-12 September 1978. World Health Organization. Geneva. 1978.

2. World Health Organization. Formulating strategies for health for all by the year 2000: guiding principles and essential issues. Document A32/8. WHO. Geneva. 1979.

3. World Health Organization. Indicators for monitoring progress towards health for all. (Discussion paper, No. HCP/225/WP 2.) WHO. Geneva. 1980.

4. Gilmartin K. J.. Rossi R. J.. Lutomski L. S. and Reed D. F. B. Social Indicators: An Annotated Bibliography of Current Literature. Garland. New York, 1979.

5. United States Department of Commerce. Bureau of the Census. Social Indicators 111. U.S. Government Printing Office. Washington. 1980.

6. Organization for Economic Cooperation and Development. Social Indicators Development Program: Final Draft of Questionnaire. Working document No. SME/ SI/CGS/79.33, OECE. Paris, 1979.

7. Andrews. F. M. Subjective social indicators objective social indicators. and social accounting systems. In Social Accounting Sistems: Essays on the State of the A $h$ (Edited by Juster F. T. and Land K. C.) Academic Press. New York, 1981.

8. Wasserman 1. M. and Chua L. A. Objective and subjective social indicators of the quality of life in American SMSA's: a reanalysis. Soc. Indicat. Res. 8, 365. 1980

9. Atkinson T., Blishen B. and Murray M. Physical status and perceived health quality. Working papers on the quality of life in Canada. York University. Institute for Behavioural Research. Downsview. Ontario, 1980.

10. Armstrong A. Health Policy and Subjectice Social Indi- cutors. Ph.D. dissertation. University of Melbournc. Melbourne. 1980.

11. Zautra A.. Kochanowicz N. and Goodhart D. Surveying quality of life in the community. Assessing Healh and Human Service Needs: Concepts. Mathods. and Ap. plications (Edited by Bell R. Sundel M.. Aponte J. and Murrell S.) Human Sciences Press. New York. 1980.

12. Goodstein J.. Zautra A and Goodhart D. A test of the utility of social indicators for behavioral health service planning. Soc. Indicat. Rex in press. 1981.

13. Land K. C. On the definition of social índicators. Am. Sociol. 6, 322. 1971 .

14. Land K. C. Social indicators models: an overview. In Social Indicaror Models (Edited by Land K. C. and Spilerman S.). Russell Sage Foundation. New York. 1975.

15. Dooley D. and Catalano R. Economic change as a cause of behavioral disorder. Psychtol. Bull. 87, 450 . 1980.

16. Juster F. T. and Land K. C. (Eds) Social Accouming Sistems: Essurs on the State of the Art. Academic Press. New York. 1981.

17. Fagnani $F$. and Dumenil $G$. Health indicators or health system analysis"? Extracts from a French survey. Soc. Indicat Res. 3. 37. 1976.

18. Andrews $F, M$. and Withey S. B. Developing measures of perceived life quality: results from several national surveys. Soc. Indicat. Res. 1, 1. 1974.

19. Andrews F. M. and Withey S. B. Social Indicators of Well-heing. Americans Perceptions of Life Quality. Plenum. New York. 1976.

20. Chen M. K. A norm-referenced population health status index based on life expectancy and disability. Soc. Inticat. Res. 5, 245, 1978.

21. Ross P. J. Bluestone H. and Hines F. K. Indicators of Social Wellheing for U.S. Colmties. Rural Development Research Report. No. 10. U.S. Department of Agriculture. Washington. 1979. 